\title{
BONE-DERIVED SECRETORY PROTEINS AND GLUCOSE AND ENERGY HOMEOSTASIS
}

\author{
Gumpeny R. Sridhar and Gumpeny Lakshmi \\ Endocrine and Diabetes Centre, Visakhapatnam, India
}

\section{Abstract}

Clinical and experimental studies demonstrate an interaction among bones, adipose tissue and diabetes mellitus: obese women have lower risk of fractures, whereas diabetes and hypertension were associated with osteopenia and osteoporosis. Today, bone is considered not solely as a supporting and protective structure, but also an active endocrine organ producing secretory proteins collectively termed osteokines. In this presentation, the role of two of these factors, leptin and osteocalcin, as well as the transcription factors FOX01 and ATF4, in the control of glucose and energy homeostasis is briefly highlighted.

Adipobiology 2010; 2:67-71

Key words: adipokines, osetokines, metabolism, skeleton

Received 15 December 2010, accepted 27 December 2010.

Correspondence: Dr Sridhar R. Gumpeny, Endocrine and Diabetes Centre, 15-12-15 Krishnanagar, Visakhapatnam 530002, India. Tel.: +91-891-2566301, E-mail: sridharvizag@gmail.com

\section{Introduction}

Metabolic diseases of glucose, lipid and of bone increase with advancing age. Diabetes mellitus is the prototype for disorders of glucose metabolism and osteoporosis of bone. Observational studies have shown that bone mineral density (BMD), a measure of bone mass, is altered in subjects with type 1 diabetes mellitus and metabolic syndrome. Recent studies have shown that in both men and women with type 2 diabetes mellitus, the prevalence of osteoporosis and of hip fracture is higher (1-3). However, the prevalence of osteoporosis was not increased in subjects with pre-diabetes (4) or with metabolic syndrome (5). A number of factors have been implicated in the dichotomy between osteoporosis in prediabetes and diabetes, namely that bone quality depends on aspects other than bone density alone, for example, bone architecture, turnover, accumulation of microdamage, mineralization and properties of bone matrix proteins (6). Advanced 
glycation end products in the bone can predispose it to fracture by interacting with its receptors (6). Subjects with type 2 diabetes mellitus enjoy little benefit from elevated BMD, in terms of improved bone load to strength ratios (7). Other risk factors such as plasma lipids (8-10) and body weight were also related to bone disorders. Many reasons have been put forth to explain the altered BMD in diabetes mellitus including increased body mass index (BMI), hyperglycemia or insulin resistance (8-10). Similarly, drugs used in osteoporosis (bisphosphonates) and dyslipidemia (statins) were shown to inhibit atherosclerosis and to also alter BMD, respectively (11). In addition, common bone-associated proteins were shown to regulate atherosclerotic plaque formation (12).

The interrelation between bone and glucose metabolism began to be unraveled with recent work on leptin and other bonederived secretory proteins (osteokines) (also see Manning's review on injured Homo obesus, in this volume of Adipobiology).

\section{Metabolism-related osteokines}

\section{Leptin}

Leptin was first discovered as endocrine product of white adipocytes, and later, in non-adipose tissues, including bone (1316). A combination of phenotypic, chemical and genetic studies suggested an integral function among leptin, bone metabolism and a central hypothalamic interaction via serotonin. Leptin deficient $(o b / o b)$ and leptin receptor-deficient $(d b / d b)$ mice were hypogonadal and had high bone mass (14). Similarly patients taking serotonin reuptake inhibitors over long periods, which increases serotonin concentrations, have been reported to exhibit low bone mass, increased appetite and weight gain. It was hypothesized that serotonin is an ancestral molecule that increases appetite; during evolution, when the skeletal system developed, serotonin took on the additional role of increasing bone formation (17). Leptin, which was first identified in vertebrates, inhibits serotonin synthesis, and thereby bone mass and appetite (17). This may represent a link between bone remodeling and energy metabolism $(18,19,20)$.

\section{Osteocalcin}

In addition to directly acting on the brain, there could be a reciprocal regulation of bone and energy metabolism by leptin and osteocalcin. Undercarboxylated osteocalcin (referred to as osteocalcin onward), a product of osteoblasts, is a hormone affecting insulin production by the pancreas and insulin sensitivity in peripheral tissues, at least in part through enhanced secretion of adiponectin from adipocytes. Osteocalcin knockout knockout mice exhibiting obesity, hyperglycemia, and decreased insulin secretion relative to wild-type mice (21-27). Leptin inhibits insulin secretion by pancreatic beta cells, while osteocalcin has the opposite effect. It acts via sympathetic innervation of osteoblasts whereby it upregulates sympathetic tone, enhances Esp expression in osteoblasts and decreases osteocalcin bioactivity. The functional relationship among adipocytes, sympathetic nervous system and osteoblasts reveals the important role skeleton can play in regulating glucose homeostasis.

The occurrence of insulin receptor in a variety of cells other than those of muscle, liver and kidney suggested insulin could have a broader role to play. In animal models developed with gain-of-function function for osteocalcin, there was increased pancreatic beta cell proliferation, as well as insulin expression and secretion. It enhanced energy expenditure and increased the adiponectin expression; the latter is a well recognized insulinsensitizing hormone secreted by the adipocytes. In vitro studies showed that beta cell proliferation and insulin expression are affected by low concentrations of osteocalcin, ranging from 0.03 to $0.3 \mathrm{ng} / \mathrm{ml}$. In vivo, low concentrations of osteocalcin upregulated insulin secretion and beta cell proliferation. Continuous delivery of osteocalcin of osteocalcin in wild type mice improved glucose load handling and decreased the mass of fat. These changes led to a decrease in obesity and type 2 diabetes mellitus.

Thus, osteoblasts and osteoclasts could contribute to glucose homeostasis, with osteoblasts acting via the hormone osteocalcin and osteoclasts acting acting through insulin mechanisms (18). There is interplay between the two cell types, where insulin signaling in osteoblasts increases osteocalcin activity, which in turn increases bone resorption (19).

Together these studies suggest that the osteokines leptin and osteocalcin exert an endocrine control on glucose and energy homeostasis (21-27).

\section{Clinical observations}

Data from a completed clinical trial involving adults aged 60 years or older $\left(n=380\right.$, mean age 71 years, BMI $26.9 \mathrm{~kg} / \mathrm{m}^{2} ; 5 \%$ had diabetes mellitus) was re-evaluated to investigate the relationship between osteocalcin concentrations and markers of metabolic syndrome (22). Interestingly, the serum osteocalcin concentrations were inversely associated with hyperglycemia, insulin resistance, systemic inflammation and body mass index. Over time, changes in osteocalcin concentrations also predicted the occurrence of hyperglycemia (20). In another study involving a Japanese cohort (171 men, 149 postmenopausal women), serum osteocalcin concentrations were inversely associated 
with glucose and adiponectin levels, fat mass and parameters of atherosclerosis in subjects with type 2 diabetes mellitus (23). A negative correlation was associated with fasting plasma glucose and glycosylated hemoglobin in both sexes. Hyperglycemia suppressed osteocalcin expression in osteoblasts. Thus serum osteocalcin secreted from osteoblasts could modulate pancreatic beta cell function and impact glucose metabolism (23). This suggests that strategies to regulate glucose metabolism can be designed by modulating the activity or production of bone-specific proteins.

\section{Metabolism-related transcription factors in bone}

Fox01 (Forkhead Box 01) expression in osteoblasts could play a role in regulating glucose metabolism through osteocalcin (28). Fox01 is a transcription factor that regulates glucose homeostasis via modulation of insulin signaling in many tissues including adipocytes, pancreatic beta cells, hepatocytes and myoblasts. In the liver cells it promotes gluconeogenesis by acting in concert with PPAR gamma coactivator, stimulating expression of glucose- 6 phosphatase and phosphoenolpyruvate kinase. Fox01 thereby controls glucose metabolism at the level of beta cell proliferation and at hepatic glucose metabolism. Rached et al (28) evaluated the function of Fox01 in other tissues, where its role is not so well known. Osteoblast-derived osteocalcin is negatively regulated by osteoblast gene, Esp. Protein tyrosine phosphatase, a product of Esp decreases the bioactivity of osteocalcin protein by favouring its carboxylation. Fox01 acts through stimulation of osteocalcin and inhibition of Esp to influence glucose metabolism via the osteoblasts. As a result, of these complementary functions it acts through osteoblast modulation to negatively regulate energy metabolism. Mice model lacking Fox01 only in osteoblasts had increased beta cell proliferation, insulin secretion and insulin sensitivity. Thus osteoblast specific Fox01 deficiency could be responsible for increased expression of osteocalcin and reduced Esp expression, the latter a gene that encodes a protein, which decreases bioactivity of osteoclasts. It appeared that Fox01 in osteoblasts controlled glucose homeostasis by regulation of both expression and carboxylation of osteocalcin as an effector molecule. The postulated mechanism involved two processes in which Fox01 directly inhibits osteocalcin expression by binding to its promoter, and promoting carboxylation. In turn, uncarboxylated osteocalcin mediates metabolic actions of osteoblasts. It also suppresses osteocalcin bioactivity by stimulating the expression of Esp. In summary, Fox01 inhibited osteocalcin expression, increased its carboxylation and led to insulin resistance, glucose intolerance and adiposity. This was the first demonstration in mammals that Fox01 to Fox01 signaling occurs between different tissues thereby resulting in Fox01 levels in bone regulating Fox01 activity in the pancreas or liver.

By coordinating the bone and pancreas through positive feedback regulation, there could be an alignment in the rate of metabolic activity between skeleton and the pancreas. In situations where the skeletal and glucose handling deteriorate such as in aging, Fox01 may "confer a rescuing signal of energy supply from the wasting skeleton to the energy demanding organs that control glucose metabolism“(28).

See Editorial on page 73-75

\section{ATF4}

ATF4 (activating transcription factor 4) accumulates predominantly in osteoblasts. It is involved in the maintenance of bone mass. Mice with Atf4-/- showed smaller fat pads than controls, it was suggested that ATF4 could have a role in energy metabolism (29). Along with other transcription factors, e.g., Runx 2 and Ostorix, ATF4 is a member of cAMP-responsive element binding protein (CREB) family of basic zipper-containing proteins. ATF4 regulates functions of the osteoblast related to the control of bone mass. In a mouse model, inactivating ATF4 enhanced the secretion of and sensitivity to insulin. However it did not affect insulin sensitivity in isolated liver cells, and could influence liver cells through another cell type. Overexpression of ATF4 in osteoblasts inhibited insulin secretion and reduced insulin sensitivity. Thus another novel pathway between bone cells and energy metabolism was shown in knockout animal model.

\section{Other associations}

\section{Osteoprotegerin and diabetes}

Osteoprotegerin (OPG) is a member of tumor necrosis factor receptor superfamily (30). It acts as a decoy receptor for receptor activator of nuclear factor-KB ligand (RANK1). Osteoprotegerin, which prevents osteoclast activation and bone resorption, is also found in many tissues including lung, heart and kidney. A recent study showed that the level of OPG was increased in subjects with diabetes. Elevated levels of OPG were predictive of all-cause mortality in type 2 diabetes mellitus independent of known conventional risk factors (30).

\section{Vitamin D and energy metabolism}

There is recent evidence that vitamin D affects energy metabolism as well as biology of adipocytes through mechanisms including the regulation of B-oxidation and expression of uncou- 
pling proteins (31). Vitamin D receptor ligands can act through the immune system to modulate the occurrence of autoimmune diseases such as type 1 diabetes mellitus (32). A recent clinical study in Arab Americans men has shown that vitamin D deficiency was associated with insulin resistance and glucose intolerance (33).

\section{Conclusion}

Studies from epidemiological, clinical, biochemical and knockout models have suggested an interaction between bone secretory activity with lipid, glucose and energy metabolism. This could further be explored in the pathogenesis and therapy of cardiometabolic diseases.

\section{References}

1. Yaturu S, Humphrey S, Landry C, Jain SK. Decreased bone mineral density in men with metabolic syndrome alone and with type 2 diabetes. Med Sci Monit 2009;15:CR5-9.

2. Bonds DE, Larson JC, Schwartz AV, Strotmeyer ES, Robbins $\mathrm{J}$, Rodriguez BL, et al. Risk of fracture in women with type 2 diabetes: the Women's Health Initiative Observational Study. J Clin Endocrinol Metab 2006;91:3404-3410.

3. Lipcombe LL, Jamal SA, Booth GL, Hawker GA. The risk of hip fracture in older individuals with diabetes. Diabetes Care 2007;30:835-841.

4. Lee JH, Lee YH, Jung KH, Ki MK, Jang HW, Kim TK, et al. Bone mineral density in prediabetic men. Korean Diabetes $J$ 2010;34:294-302.

5. Kinjo M, Setoguchi S, Solomon DH. Bone mineral density in adults with the metabolic syndrome: analysis in a population-based US sample. J Clin Endocrinol Metab 2007;92:4161-4164.

6. Yamamoto $M$, Yamaguchi $T$, Yamauchi $M$, Sugimoto $T$. Low serum level of the endogenous secretory receptor for advanced glycation end products (esRAGE) is a risk factor for prevalent vertebral fractures in dependent of bone mineral density in patients with type 2 diabetes. Diabetes Care 2009;32:2263-2268.

7. Melton LJ, Riggs BL, Leibson CL, Achenbach SJ, Camp JJ, Bouxsein ML, et al. A bone structural basis for fracture risk in diabetes. J Clin Endocrinol Metab 2008;93:4804-4809.

8. Yamaguchi T, Sugimoto T, Yano S, Yamauchi M, Sowa H, Chen $\mathrm{Q}$, et al. Plasma lipids and osteoporosis in postmenopausal women. Endocrine J 2002;49:211-217.

9. Saghafi H, Hossein-Nezhad A, Rahmani M, Larijani B. Relationship between lipid profile and bone turnover in pre and postmenopausal women. Iranian J Publ Health 2008; (Suppl 1):23-29.

10. McFarlane SI, Muniyapppa R, ShinJJ, Bahtiyar G, Sowers JR. Osteoporosis and cardiovascular disease. Endocrine 23: 1-10 DOI:1385/ENDO:23:1:01

11. Baldini V, Mastropasqua M, Francuocci CM, D’Erasmo E. Cardiovascular disease and osteoporosis. J Endocrinol Invest 2005;26 (10 Suppl):69-72.

12. Shanahan CM, Cary NRB, Metcalfe JC, Weissberg PL. High expression of genes for calcification-regulating proteins in human atherosclerotic plaques. J Clin Invest 1994;93:23932402.

13. Karsenty G. Convergence between bone and energy homeostases: leptin regulation of bone mass. Cell Metab 2006;4:341-348.

14. Karsenty G, Oury F. The central regulation of bone mass, the first link between bone remodeling and energy metabolism. J Clin Endocrinol Metab 2010;95:4795-4801.

15. Elefteriou F, Ahn JD, Takeda S, Starbuck M, Yang X, Liu X, et al. Leptin regulation of bone resorption by the sym- pathetic nervous system and CART. Nature 2005; 434:514-520.

16. Haney EM, Chan BK, Diem SJ, Ensrud KE, Cauley JA, Barrett- Connor E, et al. Association of low bone mineral density with selective serotonin reuptake inhibitor use by older men. Arch Intern Med 2007;167:1246.

17. Yadav VK, Oury F, Suda N, Liu ZW, Gao XB, Confavreux C, et al. A serotonin-dependent mechanism explains the leptin regulation of bone mass, appetite and energy expenditure. Cell 2009;138:976-989.

18. Ducy P, Amling M, Takeda S, Priemel M, Schilling AF, Beil T, et al. Leptin inhibits bone formation through a hypothalamic relay: a central control of bone mass. Cell 2000;100:197207.

19. Hinoi E,Gao N, Jung DY, Yadav V, Yoshizawa T, Kajimura, et al. An osteoblast-dependent mechanism contributes to the leptin regulation of insulin secretion. Ann NY Acad Sci 2009;1173:E20-E30

20. Ferron M, Wei J, Yoshizawa T, Fattore AD, DePinho RA, Teti A, et al. Insulin signaling in osteoblasts integrates bone remodeling and energy metabolism. Cell 2010;142:296-308

21. Ferron M, Hinoi E, Karsenty G, Ducy P. Osteocalcin differentially regulates $\mathrm{B}$ cell and adipocyte gene expression and affects the development of metabolic diseases in wild-type mice. Proc Natl Acad Sci USA 2008;105:5266-5270.

22. Pittas AG, Harris SS, Eliades M, Stark P, Hughes BD. Association between serum osteocalcin and markers of metabolic 
phenotype. J Clin Endocrinol Metab 2009;94:827-832.

23. Kanazawa I, Yamaguchi T, Yamamoto M, Yamauchi M, Kurioka S, Yano S, et al. Serum osteocalcin levels is associated with glucose metabolism and atherosclerosis parameters in type 2 diabetes mellitus. J Clin Endocrinol Metab 2009;94:45-49.

24. Hauschka PV, Lian JB, Cole DE, Gundberg CM. Osteocalcin and matrix Gla protein: vitamin K-dependent proteins in bone. Physiol Rev 1989;69:990-1047.

25. Motyl KJ, McCabe LR, Schwartz AV. Bone and glucose metabolism: a two-way street. Arch Biochem Biophys 2010; 503:2-10.

26. Lee NK, Sowa H, Hinoi E, Ferron M, Ahn JD, Confavreux $\mathrm{C}$, et al. Endocrine regulation of energy metabolism by the skeleton. Cell 2007;130: 456-469.

27. Clemens TL, Karsenty G. The osteoblast: An insulin target cell controlling glucose homeostasis. J Bone Miner Res 2010 Dec 16 (in print).

28. Rached MT, Kode A, Silva BC, Jung DY, Gray S, Ong H, et al. Fox01 expression in osteoblasts regulates glucose home- ostasis through regulation of osteocalcin in mice. J Clin Invest 2010;120:357-368.

29. Yoshizawa T, Hinoi E, Jung DY, Kajimura D, Ferron M, Seo $\mathrm{J}$, et al. The transcription factor ATF4 regulates glucose metabolism in mice through its expression in osteoblasts. J Clin Invest 2009;119:2807-2817.

30. Reinhard H, Lajer M, Gall MA, Tarnow L, Parving H, Rasmussen LM, et al. Osteoprotergin and mortality in type 2 diabetic patients. Diab Care 2010, doi:10.2337/dc10-0858.

31. Wong KE, Szeto FL, Zhang W, Ye H, Kong J, Zhang Z, et al. Involvement of the vitamin $\mathrm{D}$ receptor in energy metabolism: regulation of uncoupling proteins. Am J Physiol Endocrinol Metab 2009; 296:E820-8

32. Nagpal S, Na S, Rathnachalam R. Noncalcemic actions of vitamin D receptor ligands. Endocrine Rev 2005;26:662-687.

33. Pinelli NR, Jaber LA, Brown MB, Herman W. Serum 25-hydroxy vitamin $\mathrm{D}$ and insulin resistance, metabolic syndrome, and glucose intolerance among Arab Americans. Diabetes Care 2010;33:1373-1375. 